\title{
Características estruturais do capim-marandu diferido com alturas e doses de nitrogênio variáveis
}

\author{
Rozalino Santos, E.M. ${ }^{1}$; Resende Carvalho, B.H. ${ }^{\text {; }}$ Marçal Rodrigues, P.H. ${ }^{1}$; Cristina Basso, K. ${ }^{2}$ e Nunes de Carvalho, A. ${ }^{@}$
}

Universidade Federal de Uberlândia. Brasil.

2Universidade Federal de Santa Catarina. Brasil.

\section{PALAVRAS CHAVE ADICIONAIS}

Adubação.

Brachiaria brizantha.

Composição morfológica.

Índice de área foliar.

Pastagem.

\section{RESUMO}

Objetivou-se avaliar a contribuição de perfilhos vegetativos e reprodutivos na estrutura do capim-marandu (Urochloa brizantha syn Brachiaria brizantha cv. Marandu) diferido com alturas $(15$ e $30 \mathrm{~cm})$ e doses de nitrogênio $(0,40,80$ e $120 \mathrm{~kg}$ ha-1 de N) variáveis no início do diferimento. $O$ delineamento experimental foi inteiramente casualizado, com três repetições, sendo empregado o sistema fatorial $2 \times 4$. Houve resposta linear e positiva do número de perfilho vivo no pasto baixo em função das doses de nitrogênio. No pasto alto, a resposta ao nitrogênio sobre o número de perfilho vivo foi quadrática, com ponto de máximo aos $30 \mathrm{~kg}$ ha-1 de nitrogênio. A massa de tecido vivo, a percentagem de colmo vivo e o índice de área foliar no pasto baixo aumentaram linearmente com as doses de nitrogênio. A percentagem de lâmina foliar viva diminuiu linearmente com a aplicação de nitrogênio. A participação do perfilho reprodutivo nas massas de lâmina foliar viva e de colmo vivo, e no índice de área foliar foi menor no pasto diferido baixo, quando comparado ao alto. Os perfilhos vegetativos têm contribuição majoritária nas características estruturais dos pastos diferidos do capim-marandu diferido por 80 dias. Os efeitos do nitrogênio sobre a estrutura capim-marandu são maiores no pasto diferido baixo do que no alto. Para conciliar quantidade de forragem e estrutura do pasto, a Urochloa brizantha syn Brachiaria brizantha cv. Marandu diferida em março na região de Uberlândia pode ser rebaixada para 15 $\mathrm{cm}$ e adubada com $80 \mathrm{~kg}$ ha-l de $\mathrm{N}$.

\section{Structural characteristics of palisade grass deferred heights and nitrogen variables}

\section{SUMMARY}

The objective of this study was to evaluate the contribution of vegetative and reproductive tillers in the structure of marandu palisade grass (Urochloa brizantha syn Brachiaria brizantha cv. Marandu) with heights ( 15 and $30 \mathrm{~cm})$ and nitrogen doses $(0,40,80$ and $120 \mathrm{~kg} \mathrm{ha-1} \mathrm{of} N$ ) variables at the beginning of the deferment. The experimental design was completely randomized, with three replications, using the $2 \times 4$ factorial systems. There was a linear and positive response of the number of live tillers in the low pasture as a function of the nitrogen doses. The live tissue mass, the percentage of live stalk and the leaf area index in the low pasture increased linearly with the nitrogen doses. The percentage of live leaf blade decreased linearly with the application of nitrogen. The participation of the reproductive tiller in the masses of live leaf and live stem and in the leaf area index was lower in the low pasture when compared to the high one. The vegetative tillers have a major contribution in the structural characteristics of the deferred pastures of marandu palisade grass deferred for 80 days. The effects of nitrogen on the marandu palisade grass structure are higher in the low pasture than in the high pasture. To reconcile the amount of forage and grass structure, Urochloa brizantha syn Brachiaria brizantha cv. Marandu deferred in March in the Uberlândia region can be demoted to $15 \mathrm{~cm}$ and fertilized with $80 \mathrm{~kg} \mathrm{ha-1} \mathrm{of} \mathrm{N}$.

\section{INTRODUÇÃO}

O diferimento do uso de pastagens consiste em selecionar determinada área da propriedade e excluí-la do pastejo, geralmente no fim do verão e, ou, no outono, para garantir acúmulo de forragem a ser utilizada, via pastejo, durante o período de sua escassez de produção forrageira (Santos et al., 2009a; Santos \& Fonseca, 2016).

Em geral, o pasto diferido pode ser caracterizado por estrutura limitante ao consumo e desempenho animal, com altas massas de colmos e tecidos mortos, baixa percentagem de folhas vivas, e ocorrência de 
tombamento das plantas (Fonseca \& Santos, 2009). Para evitar esse problema, o rebaixamento do pasto no início do período de diferimento pode ser usado para remover colmos e tecidos em senescência, o que aumenta a penetração de luz até a superfície do solo e estimula o aparecimento de novos perfilhos vegetativos (Souza et al., 2012), que possuem melhores características estruturais (Santos et al., 2010a) e valor nutritivo (Santos et al., 2010b), do que perfilhos com estádio de desenvolvimento mais avançado em pasto diferido.

A adubação nitrogenada também pode ser usada, em associação com estratégias de desfolhação, para incrementar a massa de forragem produzida em pastagens diferidas (Souza et al., 2012). O efeito do nitrogênio sobre a densidade de perfilhos depende do índice de área foliar (IAF) em que o pasto é mantido. Quando o IAF é baixo, ocorre efeito positivo do nitrogênio na densidade populacional de perfilhos, pelo aumento do site filling, mas esse efeito não persiste com o desenvolvimento do IAF, o qual determina mudanças na qualidade da luz que inibe o perfilhamento (Lemaire, 2001).

Assim, tanto a adubação nitrogenada quanto a altura do pasto no início do período de diferimento influenciam o aparecimento de perfilhos vegetativos e o desenvolvimento destes até o estádio reprodutivo (Silva, 2011), o que modifica a estrutura do pasto diferido, porque os perfilhos são as unidades de desenvolvimento das gramíneas forrageiras e, portanto, mudanças no número e na morfologia de perfilhos acarretam alterações no pasto.

Desse modo, a avaliação dos perfilhos, assim como a quantificação da participação relativa das categorias de perfilhos que mais influenciam as características do pasto, permite identificar estratégias de manejo, tal como a(s) altura(s) e a(s) dose(s) de nitrogênio, que resultem em pasto diferido com adequada estrutura no inverno.

Esse trabalho foi desenvolvido para avaliar a contribuição de perfilhos vegetativos e reprodutivos sobre as características estruturais dos pastos diferidos e, com isso, identificar a(s) altura(s) e a(s) dose(s) de nitro- gênio que resultem em pasto diferido com adequada estrutura no inverno.

\section{MATERIAL E MÉTODOS}

O experimento foi conduzido de Janeiro a Julho de 2012, na Fazenda Experimental Capim Branco da Universidade Federal de Uberlândia, em Uberlândia, MG (18 53'19" S, 48 20'57" W e 863 metros de altitude). O clima da região é classificado de tropical de altitude, com estação seca e chuvosa bem definida, sendo a temperatura e precipitação média anual de $22,3{ }^{\circ} \mathrm{C}$ e $1.584 \mathrm{~mm}$ (Alvares et al., 2013). Os dados climáticos referentes ao período experimental foram obtidos em estação meteorológica localizada a $200 \mathrm{~m}$ do local do experimento (Tabela I).

Para condução do experimento, foi utilizada parte da área de uma pastagem com Urochloa brizantha syn Brachiaria brizantha cv. Marandu estabelecida no ano de 2000 e sem sinais de degradação, cujo solo foi classificado como Latossolo Vermelho Escuro Distrófico (Embrapa, 2006). As características químicas do solo da área experimental, na camada de 0 a $20 \mathrm{~cm}$, no inicio do experimento foram: $\mathrm{pH}$ em $\mathrm{H}_{2} \mathrm{O}: 6,1 ; \mathrm{P}: 2,5$ $\mathrm{mg} \mathrm{dm}{ }^{-3}$ (Mehlich-1); K: $94 \mathrm{mg} \mathrm{dm}^{-3} ; \mathrm{Ca}^{2+}: 3,1 \mathrm{cmol}_{\mathrm{c}}$ $\mathrm{dm}^{-3} ; \mathrm{Mg}^{2+}: 1,3 \mathrm{cmol}_{\mathrm{c}} \mathrm{dm}^{-3} ; \mathrm{Al}^{3+}: 0 \mathrm{cmol}_{\mathrm{c}} \mathrm{dm}^{-3}(\mathrm{KCl} 1$ mol L-1). De acordo com essas características e com as recomendações de Cantarutti et al. (1999), não houve a necessidade de realizar calagem. No inicio da época experimental, foram efetuadas de acordo com este mesmo autor, as adubações fosfatada (50 kg ha-1 de $\mathrm{P}_{2} \mathrm{O}_{5}$ na forma de superfosfato simples) e potássica (70 $\mathrm{kg} \mathrm{ha}^{-1}$ de $\mathrm{K}_{2} \mathrm{O}$ na forma de cloreto de potássio).

A área experimental foi constituída de 24 parcelas (unidades experimentais) com área de $6 \mathrm{~m}^{2}$ cada. $\mathrm{O}$ delineamento foi inteiramente casualizado, com três repetições, onde foi empregado o sistema fatorial $2 \mathrm{x}$ 4. Foram estudadas combinações entre duas alturas do dossel (15 e $30 \mathrm{~cm}$ ) e quatro doses de adubação nitrogenada $\left(0,40,80\right.$ e $120 \mathrm{~kg}^{-1}$ de $\mathrm{N}$ na forma de ureia) no inicio do período de diferimento. $\mathrm{O}$ adubo foi aplicado em Março, em cobertura no final da tarde e em dose única. Nesta mesma data de aplicação do adubo, foram estabelecidas as alturas do pasto por meio de corte mecânico, com roçadora costal e foi estabelecido o diferimento da pastagem.

Tabela I. Médias mensais de temperaturas, radiação solar, precipitação e evapotranspiração durante o período de janeiro a julho de 2012 (Average monthly temperatures, solar radiation, precipitation and evapotranspiration during the period January to July 2012)

\begin{tabular}{|c|c|c|c|c|c|c|}
\hline \multirow{2}{*}{ Mês } & \multicolumn{3}{|c|}{ Temperatura do $\operatorname{ar}\left({ }^{\circ} \mathrm{C}\right)$} & \multirow{2}{*}{$\begin{array}{l}\text { Radiação solar } \\
\text { (Mj/dia) }\end{array}$} & \multirow{2}{*}{$\begin{array}{l}\text { Precipitação } \\
\text { pluvial (mm) }\end{array}$} & \multirow{2}{*}{$\begin{array}{l}\text { Evapotranspira- } \\
\text { ção }(\mathrm{mm})\end{array}$} \\
\hline & Média & Mínima & Máxima & & & \\
\hline Janeiro & 21,7 & 18,4 & 26,9 & 16,9 & 189,4 & 82,0 \\
\hline Fevereiro & 23,1 & 18,3 & 29,4 & 20,7 & 99,0 & 97,5 \\
\hline Março & 22,8 & 18,5 & 28,9 & 18,1 & 143,2 & 88,7 \\
\hline Abril & 23,7 & 19,0 & 28,5 & 15,7 & 47,6 & 79,5 \\
\hline Maio & 20,1 & 15,4 & 24,9 & 10,6 & 10,0 & 54,3 \\
\hline Junho & 20,3 & 14,3 & 26,2 & 14,9 & 29,2 & 71,0 \\
\hline Julho & 19,1 & 12,0 & 26,3 & 16,3 & 12,8 & 83,0 \\
\hline
\end{tabular}


O capim-marandu permaneceu diferido por 80 dias, onde após este período todas as variáveis respostas foram mensuradas depois de descontada uma faixa de bordadura de 0,5 m de largura, ou seja, a mensuração das variáveis respostas ocorreu em uma área de $2 \mathrm{~m}^{2}$.

A densidade populacional de perfilho vivo foi determinada por meio da colheita de duas amostras na área útil de cada parcela, em pontos que representavam a condição média da altura. Todos os perfilhos vivos contidos no interior de um retângulo de $25 \mathrm{~cm}$ por $50 \mathrm{~cm}$ foram colhidos, com auxílio de uma tesoura de poda, ao nível da superfície do solo, acondicionados em sacos plásticos e levados para o laboratório, onde ocorreu a separação e quantificação dos perfilhos vivos em perfilhos vegetativos e reprodutivos. Os perfilhos vivos que apresentavam inflorescência visível foram classificados como reprodutivos, e os vivos que não tinham a inflorescência visível foram classificados como vegetativos.

Em cada parcela também foram colhidas duas amostras de forma aleatória, sendo uma constituída de 50 perfilhos vegetativos e a outra, de 50 perfilhos reprodutivos. Essas amostras de perfilhos foram separadas manualmente em lâmina foliar viva, lâmina foliar morta e colmo vivo + bainha foliar viva. A região da lâmina foliar que não apresentava sinais de senescência (órgão de cor intensa) foi incorporada à fração lâmina foliar viva. A região da lâmina foliar com amarelecimento e, ou, necrosamento do órgão foi descartada. As subamostras dos componentes morfológicos lâmina foliar viva e colmo + bainha vivos de cada categoria de perfilho foram acondicionadas em sacos de papel identificados, colocados na estufa de ventilação forçada, a $65^{\circ} \mathrm{C}$, por 72 horas e, em seguida, pesados. Com esses dados, foram calculadas as massas dos componentes morfológicos em cada categoria de perfilho.

As massas de forragem e dos componentes morfológicos do pasto foram obtidas pelo somatório dos produtos dos números de cada categoria de perfilho (vegetativo ou reprodutivo) pelas suas respectivas massas dos componentes morfológicos, conforme a seguinte fórmula: $\mathrm{MF}=(\mathrm{NPV} \times \mathrm{MPV})+(\mathrm{NPR} \times \mathrm{MPR})$ em que:

MF: massa de forragem ou do componente morfológico do pasto ( $\mathrm{kg} \mathrm{ha}^{-1}$ de MS);

NPV: número de perfilho vegetativo (número de perfilho $10.000 \mathrm{~m}^{-2}$ );

MPV: massa total ou do componente morfológico

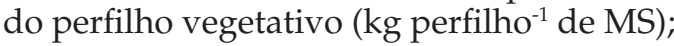

NPR: número de perfilho reprodutivo (número de perfilho $10.000 \mathrm{~m}^{-2}$ );

MPR: massa total ou do componente morfológico do perfilho reprodutivo ( $\mathrm{kg}_{\text {perfilho }}{ }^{-1}$ de $\mathrm{MS}$ ).

A partir desses resultados também foram estimadas as participações relativas dos perfilhos vegetativos e reprodutivos nas massas de forragem e dos componentes morfológicos do capim-marandu.

O índice de área foliar dos pastos diferidos foi estimado de forma indireta (Macedo et al., 2010). Para isso, de cada parcela, 50 lâminas foliares vivas foram coleta- das aleatoriamente e acondicionadas em sacos plásticos identificados. Uma pequena parte das extremidades destas lâminas foliares (ápice e base) foi cortada e descartada, de modo que a se obter um segmento de lâmina foliar aproximadamente retangular. A largura e comprimento de cada segmento foram mensurados e, pelo produto destas dimensões, obteve-se a área foliar dos segmentos de lâminas foliares. Estes foram colocados em estufa de ventilação forçada, a $65^{\circ} \mathrm{C}$, por 72 horas e, em seguida, pesados. Com esses dados, foi calculada a área foliar específica $\left(\mathrm{cm}^{2}\right.$ de lâmina foliar $\mathrm{g}^{-1}$ de lâmina foliar). A área foliar de cada categoria de perfilho foi calculada pelo produto da área foliar específica pela massa de lâmina foliar viva de cada categoria de perfilho. Por sua vez, com a multiplicação da área foliar de cada categoria de perfilho pelos números destas respectivas categorias de perfilhos obteve-se o índice de área foliar do pasto, bem como a contribuição relativa dos perfilhos vegetativos e reprodutivos nesta característica estrutural.

Todas as análises estatísticas foram realizadas ao nível de $10 \%$ de probabilidade de ocorrência do erro tipo I. Para o fator dose de nitrogênio (fator quantitativo), foram realizadas análises de regressão com seleção de modelos que melhor se ajustaram aos dados, dentro de cada altura do pasto avaliada. Os modelos foram escolhidos com base no coeficiente de determinação, bem como no padrão de resposta biológica de cada variável-resposta avaliada. Para a altura do pasto (fator qualitativo), foi aplicado o teste Tukey, para cada dose de nitrogênio estudada. Os dados foram analisados por meio do programa estatístico SAEG.

\section{RESULTADOS E DISCUSSÃO}

O número de perfilho vivo foi 31,7\% maior nos pastos manejados com $15 \mathrm{~cm}$ (pasto baixo) em relação ao pasto alto $(30 \mathrm{~cm})$, quando a maior dose de $\mathrm{N}$ (120 $\mathrm{kg}$ de $\mathrm{N} \mathrm{ha}^{-1}$ ) foi utilizada. Houve resposta linear e positiva do número de perfilho vivo no pasto baixo em função das doses de N. Porém, no pasto alto, a resposta ao nitrogênio foi quadrática com ponto de máximo aos $30 \mathrm{~kg}$ ha $^{-1}$ de N (Tabela II).

O nitrogênio estimula o perfilhamento da gramínea (Fagundes et al., 2006; Moraes et al., 2006; Caminha et al., 2010; Santos \& Fonseca, 2016), pois acelera o processo de produção de novos tecidos na planta, em razão da participação desse elemento na estrutura de proteínas, clorofila e de carreadores que participam de processos fisiológicos (Martha Júnior et al., 2004). Porém, a reposta ao nitrogênio sobre o número de perfilhos foi mais acentuada no pasto baixo devido à maior quantidade luz incidente, ocasionada pelo rebaixamento do pasto, que removeu grande quantidade de massa de forragem. A menor competição por luz e o aumento da qualidade de luz nos estratos mais baixos, provavelmente, influenciou no desenvolvimento de gemas em perfilhos (Santos et al., 2014).

Por outro lado, em pasto alto ocorreu maior sombreamento na base das plantas, especialmente quando estas tiveram sua taxa de desenvolvimento estimulada pela aplicação de nitrogênio, o que diminuiu o número de perfilhos vivos a partir da aplicação de $30 \mathrm{~kg} \mathrm{ha}^{-1}$ de 
Tabela II. Número de perfilho vivo e percentagens de perfilhos vegetativos e reprodutivos em pastos de capimmarandu manejados com alturas e doses de nitrogênio variáveis no início do período de diferimento (Number of live tillers and percentages of vegetative and reproductive tillers in marandu pastures managed with heights and levels of nitrogen variables at the beginning of the deferral period).

\begin{tabular}{|c|c|c|c|c|c|c|c|}
\hline \multirow{2}{*}{$\begin{array}{l}\text { Altura } \\
(\mathrm{cm})\end{array}$} & \multicolumn{5}{|c|}{ Dose de nitrogênio (kg/ha) } & \multirow{2}{*}{ Equação } & \multirow{2}{*}{$\mathrm{R}^{2}$} \\
\hline & 0 & 40 & & 80 & 12 & & \\
\hline & \multicolumn{7}{|c|}{ Perfilho vivo $/ \mathrm{m}^{2}$} \\
\hline 15 & $613^{a}$ & $689^{a}$ & $662^{\mathrm{a}}$ & $783^{a}$ & & $\hat{Y}=614,7+1,2008^{*} \mathrm{~N}$ & 0,76 \\
\hline \multirow[t]{2}{*}{30} & $619^{a}$ & $634^{a}$ & $596^{a}$ & $535^{b}$ & & $\hat{\mathrm{Y}}=620,12+0,7071^{*} \mathrm{~N}-0,0119^{*} \mathrm{~N}^{2}$ & 0,99 \\
\hline & \multicolumn{7}{|c|}{ Perfilho vegetativo (\%) } \\
\hline 15 & $98,5^{\mathrm{a}}$ & $96,3^{a}$ & $95,5^{\mathrm{a}}$ & $94,7^{a}$ & & $\hat{Y}=98,053-0,0300^{*} N$ & 0,92 \\
\hline \multirow[t]{2}{*}{30} & $92,0^{\mathrm{b}}$ & $91,1^{\mathrm{b}}$ & $94,2^{\mathrm{a}}$ & $91,2^{\mathrm{a}}$ & & $\bar{Y}=92,1$ & - \\
\hline & \multicolumn{7}{|c|}{ Perfilho reprodutivo (\%) } \\
\hline 15 & $1,5^{b}$ & $3,7^{b}$ & $4,5^{\mathrm{a}}$ & $5,3^{a}$ & & $\hat{\mathrm{Y}}=1,9465+0,0300^{*} \mathrm{~N}$ & 0,92 \\
\hline 30 & $8,0^{a}$ & $8,9^{a}$ & $5,8^{\mathrm{a}}$ & $8,8^{a}$ & & $\bar{Y}=7,9$ & - \\
\hline
\end{tabular}

N. Santos et al. (2009b) avaliaram períodos de diferimento e doses de nitrogênio em pastos de Brachiaria decumbens cv. Basilisk e verificaram redução no número de perfilhos vegetativos com o aumento do desenvolvimento do pasto devido à maior competição por luz.

Os pastos baixos não adubados e adubados com 40 $\mathrm{kg} \mathrm{ha}^{-1}$ de $\mathrm{N}$ apresentaram maior percentagem de perfilhos vegetativos e menor de perfilhos reprodutivos, em relação ao pasto alto. Quando maiores doses de N foram aplicadas, não houve efeito da altura inicial do pasto sobre as percentagens de perfilhos vegetativos e reprodutivos nos pastos diferidos (Tabela III).

O rebaixamento do pasto para $15 \mathrm{~cm}$, possivelmente, eliminou o meristema apical de muitos perfilhos que, assim, tiveram seu ciclo de desenvolvimento interrompido e morreram (Carvalho et al., 2016). Com isso, a rebrotação ocorreu, predominantemente a partir do desenvolvimento de novos perfilhos vegetativos. Dife- rentemente, nos pastos mais altos $(30 \mathrm{~cm})$, a rebrotação pode ter iniciado a partir de perfilhos com meristema apical remanescente. Durante o período de diferimento, esses perfilhos já existentes no pasto continuaram o seu ciclo fenológico e parte deles floresceram, o que resultou no incremento do número de perfilhos reprodutivos.

A ausência de efeitos da altura do pasto quando altas doses de $\mathrm{N}\left(80 \mathrm{e} 120 \mathrm{~kg} \mathrm{ha}^{-1}\right.$ ) foram aplicadas pode ter ocorrido em função do $\mathrm{N}$ estimular acentuadamente o desenvolvimento dos perfilhos vegetativos em reprodutivos. Esse efeito do $\mathrm{N}$ pode ter se sobreposto aos da altura do pasto, anulando os efeitos desta última. Realmente, a percentagem de perfilhos vegetativos no pasto baixo diminuiu com as doses de nitrogênio, o contrário ocorreu para a percentagem de perfilhos reprodutivos (Tabela II).

Tabela III. Características estruturais em pastos de capim-marandu manejados com alturas e doses de nitrogênio variáveis no início do período de diferimento (Structural features in marandu pastures managed with heights and nitrogen varying doses at the beginning of the deferral period).

\begin{tabular}{|c|c|c|c|c|c|c|}
\hline \multirow{2}{*}{ Altura $(\mathrm{cm})$} & \multicolumn{4}{|c|}{ Dose de nitrogênio $(\mathrm{kg} / \mathrm{ha})$} & \multirow{2}{*}{ Equação } & \multirow{2}{*}{$\mathrm{R}^{2}$} \\
\hline & 0 & 40 & 80 & 120 & & \\
\hline & \multicolumn{6}{|c|}{ Massa de tecido vivo (kg/ha de MS) } \\
\hline 15 & $3130^{b}$ & $4687^{\mathrm{b}}$ & $5237^{a}$ & $5601^{\mathrm{b}}$ & $\hat{Y}=3169,9794+35,02813^{*} \mathrm{~N}$ & 0,99 \\
\hline \multirow[t]{2}{*}{30} & $4405^{a}$ & $6281^{a}$ & $5861^{a}$ & $7409^{a}$ & $\bar{Y}=5989$ & - \\
\hline & \multicolumn{6}{|c|}{ Lâmina foliar viva (\%) } \\
\hline 15 & $67,3^{a}$ & $60,5^{\mathrm{a}}$ & $54,7^{\mathrm{a}}$ & $51,9^{a}$ & $\hat{Y}=66,3428-0,1295^{\star} N$ & 0,97 \\
\hline \multirow[t]{2}{*}{30} & $57,5^{\mathrm{b}}$ & $47,0^{\mathrm{b}}$ & $49,6^{b}$ & $46,5^{\mathrm{b}}$ & $\hat{Y}=54,6844-0,0759^{*} \mathrm{~N}$ & 0,60 \\
\hline & \multicolumn{6}{|c|}{ Colmo vivo (\%) } \\
\hline 15 & $32,8^{b}$ & $39,5^{b}$ & $45,3^{b}$ & $48,1^{b}$ & $\hat{Y}=33,6573+0,1295^{*} \mathrm{~N}$ & 0,97 \\
\hline \multirow[t]{2}{*}{30} & $42,5^{\mathrm{a}}$ & $53,0^{\mathrm{a}}$ & $50,4^{a}$ & $53,5^{\mathrm{a}}$ & $\hat{Y}=45,3157+0,0759^{*} \mathrm{~N}$ & 0,60 \\
\hline & \multicolumn{6}{|c|}{ Índice de área foliar } \\
\hline 15 & $4,0^{\mathrm{a}}$ & $5,9^{\mathrm{a}}$ & $6,2^{\mathrm{a}}$ & $6,5^{\mathrm{a}}$ & $\hat{\mathrm{Y}}=4,4902+0,0120 * \mathrm{~N}$ & 0,78 \\
\hline 30 & $4,5^{\mathrm{a}}$ & $5,3^{\mathrm{a}}$ & $5,0^{\mathrm{b}}$ & $5,1^{\mathrm{b}}$ & $\bar{Y}=5,0$ & - \\
\hline
\end{tabular}

Para cada característica, médias seguidas pela mesma letra na coluna não diferem $(P>0,10)$ pelo teste $t$; * Significativo pelo teste $t(P<0,10)$. 
Neste trabalho, independentemente das alturas e das doses de $\mathrm{N}$ usadas, houve predominância de perfilhos vegetativos (mais de $90 \%$ dos perfilhos vivos) em relação aos reprodutivos (Tabela II). Este fato pode ser justificado devido ao curto período de diferimento adotado (80 dias), que não possibilitou a diferenciação dos perfilhos vegetativos para reprodutivos. Essa assertiva encontra respaldo no trabalho de Santos et al., (2009b), que verificaram acréscimo na densidade de perfilhos vegetativos nos pastos diferidos por 73 dias em relação aos diferidos com 95 e 116 dias.

A predominância de perfilhos vegetativos é indicativo de adequada estrutura do pasto diferido, haja vista que os perfilhos vegetativos tem maior percentagem de folha viva e inferiores percentagens de colmo e folhas mortas, quando comparados aos perfilhos reprodutivos (Santos et al., 2010a). Por isso, os perfilhos vegetativos apresentam, de modo geral, superior valor nutritivo, quando comparados aos reprodutivos (Santos et al., 2010b). Contudo, vale salientar que as características morfológicas e de valor nutritivo de perfilhos vegetativos também podem ser modificadas pelas ações de manejo empregadas no diferimento do uso de pastagens, o que torna importante a caracterização morfológica dos perfilhos vegetativos e do pasto, a fim de se realizar inferências mais corretas acerta da estrutura do pasto diferido.

Nesse sentido, a avaliação de características estruturais dos pastos diferidos permitiu evidenciar aumentos lineares da massa de tecido vivo, da percentagem de colmo vivo e do índice de área foliar nos pasto baixo com o aumento das doses de nitrogênio. O pasto alto também apresentou aumento linear da percentagem de colmo vivo em função da aplicação de nitrogênio (Tabela III).

No pasto diferido com $15 \mathrm{~cm}$, os aumentos da massa de forragem viva e do índice de área foliar com a aplicação de nitrogênio podem ser explicados pelo efeito positivo do N sobre o número de perfilhos vivos (Tabela II). A maior quantidade de biomassa vegetal em pastos adubados com $\mathrm{N}$ resulta em maior competição por luz no interior do dossel e, nessa situação, como resposta morfológica, observa-se maior alongamento de colmo (Barbosa et al., 2007) para expor as folhas mais novas na parte superior do pasto. Isso pode ter sido a causa do incremento da percentagem de colmo vivo em pastos adubados com N (Tabela III). Sbrissia \& Da Silva (2001) relataram que a adubação nitrogenada acelera o processo de crescimento das plantas, podendo ocorrer o sombreamento das partes mais baixas do dossel, o que estimula o alongamento de colmos na planta em busca da captação por luz.

$\mathrm{O}$ aumento da dose de $\mathrm{N}$ diminuiu a percentagem de lâmina foliar viva no pasto diferido com as duas alturas iniciais avaliadas, porém no pasto baixo essa característica foi sempre maior $(58,6 \%$ de lâmina foliar viva) em relação ao pasto alto (50,1\% de lâmina foliar viva). É possível que, durante o período de diferimento dos pastos inicialmente mais baixos, o índice de área foliar (IAF) crítico possa ter demorado mais tempo para ser atingido. Com isso, houve menor competição por luz no interior do dossel diferido com $15 \mathrm{~cm}$, o que não promoveu acentuado sombreamento e senescência das folhas (Lemaire, 2001). A menor competição por luz no dossel manejado com menor altura também pode ser a explicação para as menores percentagens de colmo vivo nesses pastos, quando comparados àqueles diferidos mais altos (Tabela III).

A massa de tecidos vivos foi maior nos pastos diferidos com $30 \mathrm{~cm}$ em relação aos com $15 \mathrm{~cm}$, com exceção dos pastos adubados com $80 \mathrm{~kg} \mathrm{ha}^{-1}$ de N (Tabela III). Os pastos altos apresentaram inicialmente maior massa de forragem, que se somou à massa produzida durante o período de diferimento e, assim, determinou maior massa de forragem final, em comparação aos pastos baixos. Também é possível que o pasto alto (30 $\mathrm{cm}$ ) apresentasse maior índice de área foliar remanescente após o corte, o que pode ter contribuído para as maiores interceptação de luz pelo dossel, fotossíntese e taxa de crescimento do pasto. Isso explicaria o incremento da massa de forragem ao longo do período de diferimento no pasto alto, contrariamente ao ocorrido no pasto baixo (Silva, 2011).

\begin{tabular}{|c|c|c|c|c|c|c|}
\hline \multirow{2}{*}{ Altura $(\mathrm{cm})$} & \multicolumn{4}{|c|}{ Dose de nitrogênio (kg/ha) } & \multirow{2}{*}{ Equação } & \multirow{2}{*}{$\mathrm{R}^{2}$} \\
\hline & 0 & 40 & 80 & 120 & & \\
\hline & \multicolumn{6}{|c|}{ Massa de lâmina foliar viva } \\
\hline 15 & $99,3^{a}$ & $97,8^{\mathrm{a}}$ & $97,3^{\mathrm{a}}$ & $97,2^{\mathrm{a}}$ & $\bar{Y}=97,9$ & - \\
\hline \multirow[t]{2}{*}{30} & $95,4^{\mathrm{b}}$ & $93,9^{b}$ & $94,4^{\mathrm{b}}$ & $93,2^{\mathrm{b}}$ & $\bar{Y}=94,2$ & - \\
\hline & \multicolumn{6}{|c|}{ Massa de colmo vivo } \\
\hline 15 & $95,3^{\mathrm{a}}$ & $89,3^{a}$ & $85,6^{\mathrm{a}}$ & $91,3^{\mathrm{a}}$ & $\bar{Y}=83,4$ & - \\
\hline \multirow[t]{2}{*}{30} & $81,8^{b}$ & $81,9^{b}$ & $89,2^{\mathrm{a}}$ & $80,6^{\mathrm{b}}$ & $\bar{Y}=90,4$ & - \\
\hline & \multicolumn{6}{|c|}{ Índice de área foliar } \\
\hline 15 & $99,3^{\mathrm{a}}$ & $97,8^{\mathrm{a}}$ & $97,3^{a}$ & $97,2^{\mathrm{a}}$ & $\bar{Y}=97,9$ & - \\
\hline 30 & $95,4^{\mathrm{b}}$ & $93,9^{\mathrm{b}}$ & $94,4^{\mathrm{b}}$ & $93,2^{\mathrm{b}}$ & $\bar{Y}=94,2$ & - \\
\hline
\end{tabular}

Para cada característica, médias seguidas pela mesma letra na coluna não diferem $(P>0,10)$ pelo teste $t$; ${ }^{*}$ Significativo pelo teste $t(P<0,10)$. 
Table V. Relative contribution ( $\%$ ) of the reproductive tillers in the structural characteristics of marandugrass managed heights and levels of nitrogen variables at the beginning of the deferral period (Contribuição relativa (\%) do perfilho reprodutivo nas características estruturais do capim-marandu manejados com alturas e doses de nitrogênio variáveis no início do período de diferimento).

\begin{tabular}{|c|c|c|c|c|c|c|}
\hline \multirow{2}{*}{ Altura $(\mathrm{cm})$} & \multicolumn{4}{|c|}{ Dose de nitrogênio $(\mathrm{kg} / \mathrm{ha})$} & \multirow{2}{*}{ Equação } & \multirow{2}{*}{$\mathrm{R}^{2}$} \\
\hline & 0 & 40 & 80 & 120 & & \\
\hline & \multicolumn{6}{|c|}{ Massa de lâmina foliar viva } \\
\hline 15 & $0,7^{\mathrm{b}}$ & $2,2^{\mathrm{b}}$ & $2,8^{a}$ & $2,9^{b}$ & $\bar{Y}=2,2$ & - \\
\hline \multirow[t]{2}{*}{30} & $4,6^{\mathrm{a}}$ & $6,1^{\mathrm{a}}$ & $5,6^{\mathrm{a}}$ & $6,8^{\mathrm{a}}$ & $\bar{Y}=5,8$ & - \\
\hline & \multicolumn{6}{|c|}{ Massa de colmo vivo } \\
\hline 15 & $4,7^{\mathrm{b}}$ & $10,7^{\mathrm{b}}$ & $10,8^{b}$ & $8,7^{\mathrm{b}}$ & $\bar{Y}=8,7$ & - \\
\hline \multirow[t]{2}{*}{30} & $18,2^{\mathrm{a}}$ & $18,1^{\mathrm{a}}$ & $18,4^{\mathrm{a}}$ & $19,4^{\mathrm{a}}$ & $\bar{Y}=18,5$ & - \\
\hline & \multicolumn{6}{|c|}{ Índice de área foliar } \\
\hline 15 & $0,7^{\mathrm{b}}$ & $2,2^{\mathrm{b}}$ & $2,8^{b}$ & $2,9^{\mathrm{b}}$ & $\bar{Y}=2,2$ & - \\
\hline 30 & $4,6^{a}$ & $6,1^{a}$ & $5,6^{\mathrm{a}}$ & $6,8^{\mathrm{a}}$ & $\bar{Y}=5,8$ & - \\
\hline
\end{tabular}

Para cada característica, médias seguidas pela mesma letra na coluna não diferem $(P>0,10)$ pelo teste $t$; * Significativo pelo teste $t(P<0,10)$.

O índice de área foliar não diferiu com a altura do pasto quando doses de até $40 \mathrm{~kg} \mathrm{ha}^{-1}$ de $\mathrm{N}$ foram aplicadas, mas quando maiores níveis de $\mathrm{N}$ foram estabelecidos (80 e $120 \mathrm{~kg} \mathrm{ha}^{-1}$ ), o índice de área foliar do pasto diferido com $30 \mathrm{~cm}$ foi menor do que àquele com $15 \mathrm{~cm}$ (Tabela III). Esse padrão de resposta provavelmente ocorreu em virtude da diminuição do número de perfilhos vivos no pasto alto e adubado com doses de $\mathrm{N}$ acima de $30 \mathrm{~kg} \mathrm{ha}^{-1}$, fato não ocorrido naqueles pastos manejados baixos, onde o efeito do $\mathrm{N}$ sobre o perfilhamento foi linear e positivo (Tabela II).

Além disso, os pastos altos também podem ter apresentado maior senescência foliar em relação àqueles baixos, principalmente quando altas doses de $\mathrm{N}$ foram empregadas. O maior sombreamento inicial no interior dos pastos altos pode ter se intensificado quando estes tiveram seu desenvolvimento estimulado pelas altas doses de N. Como efeito, maior número de folhas, principalmente as mais velhas e localizadas no estrato basal do pasto, pode ter sido sombreado, ultrapassando o ponto de compensação luminoso, condição em que a taxa de fotossíntese é inferior à de respiração, o que ocasiona a morte foliar (Taiz \& Zeiger, 2006).

As doses de nitrogênio aplicadas no início do período de diferimento não modificaram as contribuições relativas de perfilhos vegetativos e reprodutivos nas massas de tecidos vivos e no índice de área foliar do capim-marandu diferido nos pastos baixo e alto (Tabelas IV e V). Isso pode ter ocorrido devido à predominância de perfilhos vegetativos nos pastos diferidos, o que ocorreu provavelmente em função do curto período de diferimento adotado neste trabalho (80 dias).

Ao contrário do observado para a contribuição relativa de perfilhos vegetativos (Tabela IV), a participação de perfilhos reprodutivos nas massas de lâmina foliar viva e de colmo vivo, bem como no índice de área foliar do pasto diferido foi, em geral, menor no pasto diferido com menor altura, quando comparado àquele diferido com maior altura (Tabela V).

Quando as cinco características estruturais dos pastos diferidos avaliadas neste trabalho (número de perfilhos vivos, massa de tecidos vivos, percentagens de lâmina foliar e colmo vivos e índice de área foliar) foram consideradas (Tabelas II e III), verificamos que o efeito da adubação nitrogenada foi mais efetivo quando o pasto foi manejado mais baixo. De fato, todas as características descritas da estrutura do pasto foram influenciadas pela aplicação de $\mathrm{N}$ em pasto baixo, no entanto, quando o pasto foi mantido alto, apenas três variáveis respostas $(60 \%)$ foram modificadas pelo $\mathrm{N}$.

No que tange aos efeitos da altura inicial do pasto, estes foram mais acentuados em pastos adubados com maiores doses de N (80 e $\left.120 \mathrm{~kg} \mathrm{ha}^{-1}\right)$. Nesta condição, todas as características estruturais dos pastos diferidos foram modificadas pela altura do pasto, enquanto que, com doses baixas de $\mathrm{N}\left(0\right.$ e $\left.40 \mathrm{~kg} \mathrm{ha}^{-1}\right)$, somente três variáveis respostas $(60 \%)$ foram modificadas pela altura do pasto.

Esses resultados demonstram a natureza interativa entre dose de nitrogênio e altura do pasto sobre as características estruturais do pasto diferido. Portanto, no manejo de pastagens diferidas, a adoção dos níveis de um desses fatores deve ser decidida considerando-se qual nível do outro fator que será adotado, ou seja, a escolha da dose de adubo nitrogenado dependerá da altura do pasto no início do período de diferimento e vice-versa.

\section{CONCLUSÕES}

Os perfilhos vegetativos têm contribuição majoritária nas características estruturais dos pastos diferidos do capim-marandu diferido por 80 dias. Os efeitos do nitrogênio sobre a estrutura capim-marandu são maiores no pasto diferido baixo do que no alto. Para conciliar quantidade de forragem e estrutura do pasto, a Urochloa brizantha syn Brachiaria brizantha cv. Marandu diferida em março na região de Uberlândia pode ser rebaixada para $15 \mathrm{~cm}$ e adubada com $80 \mathrm{~kg} \mathrm{ha}^{-1}$ de $\mathrm{N}$.

\section{BIBLIOGRAFIA}

Alvares, CA, Stape, JL, Sentelhas, PC, Gonçalves, JLM, \& Sparovek, G. 2013. "Köppen's climate classification map for Brazil". Meteorologische Zeitschrift, vol. 22, n. 6, p 711-728.

Barbosa, RA, Nascimento Júnior, D, Euclides, VPB, Silva, SC, Zimmer, AH, \& Torres Júnior, RAA 2007, "Capim-tanzânia submetido a combinações 
entre intensidade e freqüência de pastejo", Pesquisa Agropecuária Brasileira, Vol. 42, n. 3 pp. 329-340.

Caminha, FO, Silva SC, Paiva, AJ, Pereira, LETP, Mesquita, P, \& Guarda, VDA. 2010. "Stability of tiller population of continuously stocked marandu Palisade grass fertilized with nitrogen". Pesquisa Agropecuária Brasileira, v. 45, n. 2, p. 213-220.

Cantarutti, RB, Martins, CE, Carvalho, MM, Fonseca, DM, Arruda, ML, Vilela, H, \& Oliveira, FTT 1999, "Pastagens". In: Ribeiro, AC, Guimarães, PTG, Alvarez, VVH, Comissão de Fertilidade do Solo do Estado de Minas Gerais, Recomendação para o uso de corretivos e fertilizantes em Minas Gerais, Viçosa - 5^a Aproximação, pp. 332 - 341.

Carvalho, RM, Carvalho, BHR, Fernandes, WB, Alves, KM, Sousa, DOC, Silva, GF, \& Santos, MER. 2016. "Rebaixamento do capim marandu para o diferimento e seus efeitos sobre índice de área foliar e número de meristemas apicais". Boletim de Indústria Animal, v. 73, n. 3

EMBRAPA. 2006. Sistema brasileiro de classificação de solos. 2nd ed. Rio de Janeiro: Embrapa Solos, 306p.

Fagundes, JL, Fonseca, DM, Morais, RV, Mistura, C, Vitor, CMT, Gomide, JA, Nascimento Júnior, D, Santos, MER, \& Lambertucci, DM 2006, "Avaliação das características estruturais do capim-braquiária em pastagens adubadas com nitrogênio nas quatro estações do ano", Revista Brasileira de Zootecnia, Vol. 35, n. 1 pp. 30-37.

Fonseca, DM \& Santos, MER. 2009. "Diferimento de pastagens: estratégias e ações de manejo", In: Anais do $6^{\circ}$ Simpósio de forragicultura e pastagem e $3^{\circ}$ Congresso de forragicultura e pastagem, Lavras, Brasil, pp. 65-88.

Kopen, W 1948, "Climatologia", Buenos Aires, Argentina, Gráfica Pan-Americana.

Lemaire, G 2001, "Ecophisiology of grasslands: dynamic aspects of forage plant populations in grazed swards", In: $19^{\circ}$ Proceedings International grassland congress, São Pedro, Brasil pp. 29-37.

Macedo, CHO, Alexandrino, E, Jakelaitis, A, Vaz, RGMV, Reis, RHP, \& Vendrusculo, J 2010, "Características agronômicas, morfogênicas e estruturais do capim Panicum maximum cv. Mombaça sob desfolhação intermitente", Revista Brasileira de Saúde e Produção Animal, Vol. 11, n. 4 pp. 941-952.

Martha Júnior, GB, Vilela, L, Barioni, LG, et al. 2004, "Manejo da adubação nitrogenada em pastagens", In: Anais do $21^{\circ}$ Simpósio sobre manejo da pastagem, Piracicaba, Brasil pp.155-216.

Morais, RV, Fonseca, DM, Nascimento Junior, D, Ribeiro Junior, Jl, Fagundes, JL, Moreira, LM, Mistura, C, \& Muscello, JA. 2006. "Demografia de perfilhos basilares em pastagem de Brachiaria decumbens adubada com N". Revista Brasileira de Zootecnia, v.35, n.2, p.380-388.

Santos, MER, Fonseca, DM, Balbino, EM, Monnerat, JPIS, \& Silva, SP, 2009a, "Capim-braquiária diferido e adubado com nitrogênio: produção e características da forragem" , Revista Brasileira de Zootecnia, Vol. 38, n. 4 pp. 650-656.

Santos, MER, Fonseca, DM, Balbino, EM, Monnerat, JPIS, \& Silva, SP, 2009b, "Caracterização de perfilhos em pastos de capim-braquiária diferidos eadubados com nitrogênio", Revista Brasileira de Zootecnia, Vol. 38, n. 4 pp. 643-649.

Santos, MER, Fonseca, DM, Balbino, EM, Silva, SP, Monnerat, JPIS, \& Gomes, V 2010a, "Características estruturais de perfilhos vegetativos e reprodutivos em pastos diferidos de capim-braquiária", Ciência Animal Brasileira, Vol. 11, n. 3 pp. 492-502.

Santos, MER, Fonseca, DM, Balbino, EM, Silva, SP, \& Monnerat, JPIS 2010b, "Valor nutritivo de perfilhos e componentes morfológicos em pastos de capim Braquiária diferidos e adubados com nitrogênio" Revista Brasileira de Zootecnia, Vol. 39, n. 9 pp.1919-1927.

Santos, MER, Gomes, VM, Fonseca, DM, Albino, RL, Silva, SP, \& Santos, AL 2011, "Número de perfilhos do capim-braquiária em regime de lotação contínua", Acta Scientiarum, Vol. 33, n. 1 pp. 1-7.

Santos, MER, Fonseca, DM. Adubação de pastagens em sistemas de produção animal. Viçosa (MG): Editora UFV, 2016. $311 \mathrm{p}$.

Sbrissia, AF \& Silva, SC, 2008, "Compensação tamanho/densidade populacional de perfilhos em pastos de capim-marandu", Revista Brasileira de Zootecnia, Vol. 37, n. 1 pp. 35-47.

Silva, AAS, 2011, "Altura inicial e adubação nitrogenada em pastos diferidos de capim-braquiária", Dissertação (Mestrado em Zootecnia) - Universidade Federal de Viçosa, Viçosa.

Souza, BML, Vilela, HH, Santos, AL, Santos, MER, Júnior, DN, Assis, CZ, Faria, BD, \& Rocha, GO 2012, "Piata palisadegrass deferred in the fall: effects of initial height and nitrogen in the sward structure", Revista Brasileira de Zootecnia, Vol. 41, n. 5 pp. 1134-1139.

Taiz, L \& Zeiger, E, 2006, "Fisiologia Vegetal", Porto Alegre, Artmed, Ed. 3, pp. 719. 